\title{
Specialty Choice and Labor Market Outcomes of Foreign Medical Graduates
}

\author{
Stuti Jha \\ Rowan University
}

I analyze the labor market outcome of foreign medical graduates (FMGs) in the US. I look at the institutional bottlenecks these physicians face to enter the US and its impact on their labor market outcome. I use the Community Tracking Survey's Physician survey data to compare earnings of the two groups of physicians using regression analysis. My analysis shows the importance of specialty sorting in determining the income profile of a physician, and in particular the reason for the higher likelihood of FMGs to be in primary care specialty and the resulting lower earnings for a FMG.

Keywords: Physicians, Residency, Specialty Choice, Wages, FMG

\section{INTRODUCTION}

Like many developed countries, the US faces a shortage of physicians in rural and high density poor urban areas. According to AAMC estimates, the United States faces a shortage of more than 90,000 physicians by 2020 - a number that will grow to more than 130,000 by 2025 . The healthcare sector relies heavily on foreign medical graduates (FMGs) to provide the required support in medically underserved areas of the country. The department of Health \& Human services designate a MUA after looking at four variables, ratio of primary medical care physicians per 1,000 population, infant mortality rate, percentage of the population with incomes below the poverty level, and percentage of the population age 65 or over. According to the American Medical Association (AMA) estimates, FMGs make up almost $1 / 4^{\text {th }}$ of the total physician population in the US (AMA Workforce Report (2011)). Experts believe that passing of the Affordable Care Act has worsened the shortage of physicians especially in the primary care sector due to increase in number of patients with insurance coverage (Petterson et. al. (2010). Various media outlets, organization like AAMC and AARP, have raised concerns over the increase in demand for physicians the law will create with no immediate increase in supply of domestic medical students. The supply of US medical graduates (USMGs) in the country is capped due to fixed number of medical schools in the country. Thus, the US reliance on FMGs is expected to increase in the near future.

Despite the importance of FMGs, not much research in the economics literature has focused on the labor market outcomes of these doctors. A study by McDonald, Warman and Worswick (2011) looks at the entry barriers for FMGs into the US and Canada, based on differences in their immigration policy, and how these differences affect the likelihood of working as a physician for these immigrants. They find that immigrants in US have a better likelihood of working as physician than in Canada.

All Physicians seeking to practice in the US must first complete a hospital residency program in their chosen specialty. We find that the specialty choice is the biggest institutional constraint in determining a 
physician's lifetime earning profile. Match data available from the National Residency Matching Program (NRMP), the agency responsible for matching residency positions to applicants, indicates that a FMG applicant seeking a residency in the US is more likely to be accepted in the primary care field than in other medical specialties (Results and Data, 2018 Residency Match, The National Residency Matching Program). We analyse data to show the over representation of FMGs in low paying primary care specialties and it's implication on earnings of FMGs across specialty areas.

We use the Community Tracking Physician survey restricted dataset in this paper to study the difference in earnings of FMGs and USMGs. We use data from all five rounds of survey for our analysis. The survey collected responses from physicians working mre than ten hours a week, and include variables related to specialty choice, practice setting choice, demographic variables and their annual earning before taxes. For this paper, we restrict our data to physicians working at least 20 hours or more per week.

\section{LITERATURE REVIEW}

The debate surrounding FMGs role in the US health care market varies from one study to the other. The reason for opening the borders to these doctors in 1982 was to address the possible shortage of physicians in the market. However, some studies argue that there is over supply of physicians and therefore entry of the FMGs should be restricted (Pew Health Professions Commission , Critical Challenges: Revitalizing the Health Professions for the Twenty-first Century: Third Report of the Pew Health Professions Commission ( San Francisco : University of California at San Francisco Center for the Health Professions , 1995)). Non-US born FMGs who practice in the USA either arrive on H1B visas or under the exchange visa program J-1. Mullan et. al. (1995) find that most of the FMGs on the exchange visa end up practicing in the USA itself. They also show that most of the FMGs sub specialize within primary care thus questioning their role as the safety-net of America's health care system. As a result, the authors argue that there should be restrictions placed on the entry of these physicians.

Despite few studies above, studies have shown that FMGs are more likely to serve in medically underserved areas, and they specialize in primary care specialty at disproportionately higher rates (Mick et.al. (1997); Hart et. al. (2007), Thompson et. al. (2009)), Fordyce et. al. (2012). However, the studies also show that FMGs are less likely to serve in rural underserved areas. On the other hand, some studies show that FMGs make up a higher proportion of the rural physician work force (Baer (1998)). In fact, FMGs have become an essential part of the physician labor force leading to creation of several professional associations catering to their needs and interests in several states (Mick et. al (1997)). As a result, the medical community is taking steps to integrate the immigrant doctors in American culture as it has been shown that FMGs face challenges in practicing in the USA. Sometimes the transition from home country to their new adoptive country isn't very smooth (Chen et. al. (2010).

Much of the debate about the role of FMGs centers around the quality of care provided by the FMGs. However, very little research has been done to empirically test the outcome measures of these physicians. Several studies have looked at the outcomes for patients treated by the two groups of physicians. Norcini et. al. (2010) used hospital records of patients treated by physicians from the state of Pennsylvania. They found that patients treated by FMGs have a lower mortality rate than patients treated by USMGs. Tsugawa (2017) more recently showed similar results for Medicare patients across the USA. Mick (1997) in his literature review concluded that evidence of lower quality of care provided by the FMGs does not exist. Alam et. al. (2017) compared the rate at which international medical graduates were disciplined by professional regulatory committees to Canadian medical graduates. They found the FMGs were disciplined at a much higher rate. They didn't analyze the type of misconduct or disciplinary action so it is not clear if it is due to bias or some other group characteristics. None of the studies, however, show the earnings differential between the two groups. 


\section{DATA}

\section{Data Description - CTS Physician Survey}

We use the restricted data files of the Community Tracking Survey (Physicians), a project of Health System Change, for the years 1996-97, 1998-99, 1999-2000, and 2004-05. CTS Physician survey includes responses from a sample of active full time physicians, who have completed their medical training, are currently working in the USA, and provide direct patient care for more than 20 hours every week. The survey collects information on physician's basic demography like age, gender and race; medical practice arrangements, revenue sources, level of physician compensation, physicians' allocation of time, and career satisfaction etc. The specialties are divided into two broad categories, primary care, and nonprimary care specialties. A primary care physician is identified as one working in one of the following sub specialties: internal medicine, pediatrics, family practice, psychiatry, and ob-gyn.

The survey covers 60 communities across the country based on the geographic and demographic constituents, but it includes weights that can be used to get national level estimates. The summary statistics given in table 1 is consistent with the AMA masterfile data on physicians, i.e. FMGs are older and more experienced as compared to USMGs. The average age of FMGs is 48 years as compared to 45.5 years for USMGs.

Some other statistics important for our results is the proportion of FMGs in low paying specialties, and low paying practice settings. 46 per cent of FMGs are in solo practice and approx. 20 per cent are working in group practices, while the number for USMGs is 32 per cent and 33 per cent respectively. Also, 64 per cent of FMGs are working as primary care physicians as against 56 per cent of USMGs. Most of the FMGs do enter primary care because of certain institutional barriers such as finding a residency position through the match program and Government's visa regulations regarding foreign physicians practicing in the USA. In 1994, Senator Kent Conrad (North Dakota) addressed the issue of physician shortages in rural and urban areas of the United States by formulating the Conrad J1 visa waiver program. The Conrad program allowed each State's Department of Health to sponsor up to a certain number (initially 20, and now 30) foreign medical graduates (FMGSs) each year for waiver of the two-year home residency requirement of the physician's J1 visa.

TABLE 1

SUMMARY STATISTICS

\begin{tabular}{|l|l|l|l|l|l|l|l|l|}
\hline & FMG $(\mathrm{n}=8383)$ & & & \multicolumn{3}{l|}{ USMG (n=32,016) } & & \\
\hline & Mean & Std. Dev. & Min & Max & Mean & Std. Dev. & Min & Max \\
\hline $\begin{array}{l}\text { Hourly } \\
\text { Income }(\$)\end{array}$ & 66.31 & 42.4 & 3.47 & 787.34 & 69.691 & 40.85 & 2.72 & 730.85 \\
\hline Age & 48.09 & 8.62 & 27 & 65 & 45.467 & 8.501 & 26 & 65 \\
\hline Experience & 14.14 & 9.04 & 0 & 43 & 13.953 & 8.702 & 0 & 43 \\
\hline Male & 0.754 & & & & 0.7781 & & & \\
\hline Solo & 0.461 & & & & 0.3228 & & & \\
\hline Group & 0.198 & & & & 0.3295 & & & \\
\hline HMO & 0.047 & & & & 0.046 & & & \\
\hline Hospital & 0.134 & & & & 0.116 & & & \\
\hline $\begin{array}{l}\text { Medical } \\
\text { school }\end{array}$ & 0.064 & & & & 0.086 & & & \\
\hline Other & 0.094 & & & & 0.098 & & & \\
\hline PCP & 0.641 & & & & 0.566 & & & \\
\hline $\begin{array}{l}\text { Board } \\
\text { Certification }\end{array}$ & 0.778 & 0.415 & & & 0.9003 & 0.299 & & \\
\hline
\end{tabular}


Notes: Summary statistics of Community Tracking Survey data for the years 1996-97, 1998-99, 1999-2000, and 2004-05. The table shows individual specific variables, practice setting variables (solo, group etc.) and specialty choice of a physician. FMG- foreign medical school graduates; USMG- US medical school graduates. PCP primary care physician (internal medicine, family medicine, psychiatry, pediatrician, ob-gyn).

Nine out of ten USMGs are board certified, which carries a premium of 8 to 14 per cent, depending on the specialty a physician is working in. FMGs have a much lower rate of board certification (78 per cent), but this could be because the benefits to board certified physician is much higher for medical specialties than for primary care. For empirical analysis, we dropped all variables with missing income variable and everyone with annual income lower than $\$ 20,000$, where the annual income variable is top coded at $\$ 400,000$. Everyone above the age of 65 years was dropped, so I include physicians within the working age population.

CTS data doesn't report the country of origin and/or country of medical schooling of the physicians. This makes comparisons based on home country characteristics impossible. It is reasonable to assume that labor market outcomes of FMGs, whether immigrant or US citizens, will depend on the quality of medical education and infrastructure, reputation and ethnic linkages of their home country. However, since we have looked at the match rates of FMGs and USMGs under the NRMP, my results are not negatively affected by this lack of data.

\section{Empirical Framework}

We run an ordinary least squares regression to measure the impact of demographic variables like age, experience and gender, and other practice related variables on the wages of physicians. The data includes information on number of hours worked in a week, and number of weeks worked in a year, which is used to calculate the dependent variable, log hourly income.

Wage Equation:

$Y_{k l r}=\beta_{0}+\beta_{1} M_{k l r}+\beta_{2} S_{k l r}+\beta_{3} X_{k l r}+T_{r}+g_{l}+d_{t}+\varepsilon_{k l r}$

$Y_{k l r}$ is log hourly income of the $k^{\text {th }}$ physician, working in $l^{\text {th }}$ location, in practice setting $r$. $\mathrm{X}$ is a vector of personal characteristics like age, experience, gender and race variables. $\mathrm{M}$ is an indicator variable for foreign medical graduates.

$\mathrm{S}$ is an indicator for primary care physician, which takes a value of one if the physician works in one of the five primary care specialties, and zero otherwise. This is the most important determinant of physician's earnings, since the average salary for these two specialty groups differ substantially. Primary care physicians earn much less than non-primary care physicians, and as shown in previous sections, FMGs are more likely to work as primary care physician. $T_{r,} g_{l} \& d_{t}$ are practice setting, location and time fixed effects.

A physician can either be self-employed or work as an employee for another organization. The various organizational settings include solo practice, group practice, health management organization, hospital, and medical school. Income of physicians across locations and practice settings differ substantially. Physicians working in urban areas earn more than those working in rural areas. Also, group practices are most remunerative than any other practice setting, and most of the USMGs work in group practices. FMGs are selected into solo practices or hospitals, which have lower earning potential.

\section{RESULTS}

Table 2 gives the results of OLS regression of log hourly income of physicians on variables specified in the empirical model. Column 1 of the table includes only the personal characteristics like age, experience, quadratic in experience, and gender. After controlling for these variables, the difference in earnings for FMGs is 6.12 per cent, that is, on average, FMGs earn 6 per cent less than the USMGs. 
Physicians with an additional year of experience earn 3 per cent more, but the quadratic term is negative indicating a declining experience earning profile. The coefficient on dummy for gender shows that male physician earn approximately 17 per cent higher than female physicians. This difference is reduced to 10 per cent when we control for organizational setting and specialty choices (see column 3 of table 2). Like FMGs, female physicians are also more likely to be in primary care specialties and hence earn less than men.

TABLE 2

OLS REGRESSION OF LOG HOURLY INCOME ON FMG AND OTHER VARIABLES

\begin{tabular}{|c|c|c|c|c|}
\hline VARIABLES & (1) & $(2)$ & (3) & (4) \\
\hline & \multicolumn{4}{|c|}{ Log Hourly Income } \\
\hline \multirow[t]{2}{*}{ FMG } & $-0.0612 * * *$ & $-0.0490 * * *$ & $-0.0363 * * *$ & -0.00679 \\
\hline & $(0.0111)$ & $(0.0109)$ & $(0.0109)$ & $(0.0105)$ \\
\hline \multirow[t]{2}{*}{ Age } & $-9.78 e-05$ & 0.00105 & $0.00212 *$ & $-0.00257 * *$ \\
\hline & $(0.00111)$ & $(0.00109)$ & $(0.00110)$ & $(0.00102)$ \\
\hline \multirow[t]{2}{*}{ Experience } & $0.0333 * * *$ & $0.0319 * * *$ & $0.0295 * * *$ & $0.0309 * * *$ \\
\hline & $(0.00184)$ & $(0.00182)$ & $(0.00183)$ & $(0.00174)$ \\
\hline \multirow[t]{2}{*}{ Experience Squared } & $-0.000812 * * *$ & $-0.000780 * * *$ & $-0.000727 * * *$ & $-0.000658 * * *$ \\
\hline & $(4.77 \mathrm{e}-05)$ & $(4.69 \mathrm{e}-05)$ & $(4.71 \mathrm{e}-05)$ & $(4.65 \mathrm{e}-05)$ \\
\hline \multirow[t]{2}{*}{ Male } & $0.167 * * *$ & $0.157 * * *$ & $0.155 * * *$ & $0.108 * * *$ \\
\hline & $(0.0106)$ & $(0.0106)$ & $(0.0107)$ & $(0.0101)$ \\
\hline \multirow[t]{2}{*}{ Solo } & & $-0.185 * * *$ & $-0.177 * * *$ & $-0.169 * * *$ \\
\hline & & $(0.0105)$ & $(0.0106)$ & $(0.0101)$ \\
\hline \multirow[t]{2}{*}{ Hospital } & & $-0.124 * * *$ & $-0.117 * * *$ & $-0.0876^{* * *}$ \\
\hline & & $(0.0129)$ & $(0.0128)$ & $(0.0128)$ \\
\hline \multirow[t]{2}{*}{$\mathrm{HMO}$} & & -0.0189 & -0.0193 & $0.0287 *$ \\
\hline & & $(0.0179)$ & $(0.0179)$ & $(0.0162)$ \\
\hline \multirow[t]{2}{*}{ Medical School } & & $-0.240 * * *$ & $-0.240 * * *$ & $-0.273 * * *$ \\
\hline & & $(0.0146)$ & $(0.0145)$ & $(0.0142)$ \\
\hline \multirow[t]{2}{*}{ Other } & & $-0.149 * * *$ & $-0.138^{* * *}$ & $-0.103 * * *$ \\
\hline & & $(0.0136)$ & $(0.0136)$ & $(0.0127)$ \\
\hline \multirow[t]{2}{*}{ Board Certified } & & & $0.147 * * *$ & $0.125 * * *$ \\
\hline & & & $(0.0137)$ & $(0.0131)$ \\
\hline \multirow[t]{2}{*}{ PCP } & & & & $-0.299 * * *$ \\
\hline & & & & $(0.00757)$ \\
\hline \multirow[t]{2}{*}{ Constant } & $3.716 * * *$ & $3.795 * * *$ & $3.632 * * *$ & $3.959 * * *$ \\
\hline & $(0.0391)$ & $(0.0393)$ & $(0.0418)$ & $(0.0398)$ \\
\hline Observations & 40,399 & 40,399 & 40,399 & 40,399 \\
\hline R-squared & 0.081 & 0.106 & 0.113 & 0.180 \\
\hline
\end{tabular}

Note: column 1 of the table includes only the individual specific variables like age, experience, gender. As we add practice setting and specialty controls, the coefficient of FMG goes down. Column 4 includes dummy for being a primary care physician and we can see that the coefficient is not different from zero. FMG- foreign medical school graduates; PCP - primary care physician (internal medicine, family medicine, psychiatry, pediatrician, OB-Gyn).

Column 2 - 4 of table 2 include practice setting options of physicians and dummy for primary care physician respectively. A physician's practice choice explains some of the difference in earnings, but as column 2 shows, a 4.9 per cent wage gap between the two groups of physicians still remains. Most of 
USMGs (almost 33 per cent) work in group practices, which are the highest paid settings for physicians. On the other hand, one in every two FMGs works in a solo practice. Research on earnings in different practice settings around the world has shown that physicians working in group practices earn higher than those working in solo practice. Lin (2006) compared the earnings of 7757 Taiwanese physicians based on practice settings and concluded that physicians in group practice earn much more than solo practitioners. FMGs may prefer solo practices to other type of settings due to other benefits associated with going solo, including setting up practice in a preferred location like an ethnic enclave, and greater autonomy in the operations of the practice. In the regression, with group practice the control group, one can see that physicians in other practice settings are doing much worse, with solo practitioners earning 18 per cent less in hourly income.

Board certification is an important quality indicator of a physician. Bornstein, Marcus and Cassidy (2000) did a survey of patients to show that board certification status is an important factor for patients in their search for a physician. A board certified doctor on average earns $15 \%$ more than the non-certified doctor so there is a premium to get certified. Again, FMGs are less likely to be board certified than USMGS, so adding this dummy further reduces the wage differential to $3.5 \%$. Finally, we add the dummy for specialty choice, which indicates whether the physician is in primary care specialty or not eliminates the entire wage differential between FMGs and USMGs. The coefficient for FMGs is not significantly different from zero in the 4 th column of table 2.

TABLE 3

\section{OLS REGRESSION OF LOG HOURLY INCOME ON DATE FROM FMGS \& USMGS SEPARATELY}

\begin{tabular}{|c|c|c|}
\hline & (FMG) & (USMG) \\
\hline VARIABLES & \multicolumn{2}{|c|}{ Log Hourly Income } \\
\hline \multirow[t]{2}{*}{ Age } & -0.00180 & $-0.00407 * * *$ \\
\hline & (0.00188) & $(0.00122)$ \\
\hline \multirow{2}{*}{ Experience } & $0.0232 * * *$ & $0.0338 * * *$ \\
\hline & $(0.00405)$ & $(0.00194)$ \\
\hline \multirow[t]{2}{*}{ Experience Squared } & $-0.000509 * * *$ & $-0.000688 * * *$ \\
\hline & $(0.000118)$ & $(4.92 \mathrm{e}-05)$ \\
\hline \multirow[t]{2}{*}{ Male } & $0.0854 * * *$ & $0.112 * * *$ \\
\hline & $(0.0205)$ & $(0.0116)$ \\
\hline \multirow[t]{2}{*}{ Solo } & $-0.150 * * *$ & $-0.171 * * *$ \\
\hline & $(0.0228)$ & $(0.0111)$ \\
\hline \multirow[t]{2}{*}{ Hospital } & $-0.0912 * * *$ & $-0.0857 * * *$ \\
\hline & $(0.0342)$ & $(0.0129)$ \\
\hline \multirow[t]{2}{*}{$\mathrm{HMO}$} & 0.0303 & $0.0330^{*}$ \\
\hline & $(0.0351)$ & $(0.0181)$ \\
\hline \multirow[t]{2}{*}{ Medical School } & $-0.236 * * *$ & $-0.275 * * *$ \\
\hline & $(0.0357)$ & $(0.0156)$ \\
\hline \multirow[t]{2}{*}{ Other } & $-0.0820 * * *$ & $-0.106 * * *$ \\
\hline & $(0.0282)$ & $(0.0142)$ \\
\hline \multirow[t]{2}{*}{ Board Certified } & $0.0885 * * *$ & $0.141^{* * *}$ \\
\hline & $(0.0226)$ & $(0.0158)$ \\
\hline \multirow[t]{2}{*}{ PCP } & $-0.266 * * *$ & $-0.312 * * *$ \\
\hline & $(0.0192)$ & $(0.00816)$ \\
\hline
\end{tabular}




\begin{tabular}{|l|c|c|}
\hline Constant & $4.016^{* * *}$ & $3.981 * * *$ \\
\hline & $(0.0811)$ & $(0.0470)$ \\
\hline Observations & 8,383 & 32,016 \\
\hline R-squared & 0.137 & 0.198 \\
\hline
\end{tabular}

Notes: the table shows the influence of different variables on the two groups of physicians. We can see that the difference in earnings between primary care and non-primary care physicians is lower for FMGs. This supports our claim that more high ability FMGs enter primary care. FMG- foreign medical school graduates; PCP - primary care physician (internal medicine, family medicine, psychiatry, pediatrician, OB-Gyn).

TABLE 4

OLS REGRESSION FOR PRIMARY CARE PHYSICIANS VS. NON-PRIMARY CARE PHYSICIANS

\begin{tabular}{|c|c|c|c|}
\hline & (PCP) & (NPCP) & All \\
\hline VARIABLES & \multicolumn{3}{|c|}{ Log Hourly Income } \\
\hline \multirow[t]{2}{*}{ FMGS } & $0.0250 *$ & $-0.0292 * *$ & $-0.0316^{* *}$ \\
\hline & $(0.0141)$ & $(0.0147)$ & $(0.0145)$ \\
\hline \multirow[t]{2}{*}{ Age } & $-0.00545 * * *$ & -0.000617 & $-0.00275 * * *$ \\
\hline & $(0.00117)$ & $(0.00159)$ & $(0.00103)$ \\
\hline \multirow[t]{2}{*}{ Experience } & $0.0288 * * *$ & $0.0337 * * *$ & $0.0312 * * *$ \\
\hline & $(0.00202)$ & $(0.00262)$ & $(0.00175)$ \\
\hline \multirow[t]{2}{*}{ Experience Squared } & $-0.000465 * * *$ & $-0.000823 * * *$ & $-0.000659 * * *$ \\
\hline & $(5.83 \mathrm{e}-05)$ & $(6.66 \mathrm{e}-05)$ & $(4.64 \mathrm{e}-05)$ \\
\hline \multirow[t]{2}{*}{ Male } & $0.0917 * * *$ & $0.123 * * *$ & $0.109 * * *$ \\
\hline & $(0.0112)$ & $(0.0159)$ & $(0.0101)$ \\
\hline \multirow[t]{2}{*}{ Solo } & $-0.158 * * *$ & $-0.173 * * *$ & $-0.170 * * *$ \\
\hline & $(0.0135)$ & $(0.0136)$ & $(0.0101)$ \\
\hline \multirow[t]{2}{*}{ Hospital } & 0.0229 & $-0.159 * * *$ & $-0.0859^{* * *}$ \\
\hline & $(0.0158)$ & $(0.0184)$ & $(0.0128)$ \\
\hline \multirow[t]{2}{*}{$\mathrm{HMO}$} & $0.0552 * * *$ & 0.0225 & $0.0289 *$ \\
\hline & $(0.0174)$ & $(0.0259)$ & $(0.0161)$ \\
\hline \multirow[t]{2}{*}{ Medical School } & $-0.109 * * *$ & $-0.326 * * *$ & $-0.272 * * *$ \\
\hline & $(0.0174)$ & $(0.0184)$ & $(0.0142)$ \\
\hline \multirow[t]{2}{*}{ Other } & $-0.0347 * *$ & $-0.152 * * *$ & $-0.103 * * *$ \\
\hline & $(0.0146)$ & $(0.0197)$ & $(0.0127)$ \\
\hline \multirow[t]{2}{*}{ Board Certified } & $0.0995 * * *$ & $0.136 * * *$ & $0.127 * * *$ \\
\hline & $(0.0164)$ & $(0.0195)$ & $(0.0131)$ \\
\hline \multirow[t]{2}{*}{ PCP } & & & $-0.312 * * *$ \\
\hline & & & $(0.00812)$ \\
\hline \multirow[t]{2}{*}{ FMG*PCP } & & & $0.0602 * * *$ \\
\hline & & & $(0.0198)$ \\
\hline \multirow[t]{2}{*}{ Constant } & $3.762 * * *$ & $3.873 * * *$ & $3.967 * * *$ \\
\hline & $(0.0450)$ & $(0.0607)$ & $(0.0400)$ \\
\hline Observations & 23,264 & 17,135 & 40,399 \\
\hline R-squared & 0.104 & 0.121 & 0.181 \\
\hline
\end{tabular}

Notes: in this table we divide the data into primary care and non-primary care. FMGs in primary care do better than USMGs but they earn lower in non-primary care sector. Table 5 on next page helps explain this gap. The last 
column includes an interaction term between FMG and primary care. FMG- foreign medical school graduates; PCP - primary care physician (internal medicine, family medicine, psychiatry, pediatrician, OB-Gyn).

Tables 3 and 4 give the results of regressions for FMGs and USMGs; and primary care and nonprimary care physicians respectively. A look at the coefficients in table 3 tells us that FMGs on average have worse outcomes for all variables. A male physician earns more than female physician in both the groups but the difference is higher for USMGs. Return to experience and return to board certification is also higher for USMGs. However, the wage gap between primary care and non-primary care physician is much wider for USMGs.

To understand the effect of specialty choice, we run separate regressions for primary care and nonprimary care physicians. The results in table 4 show that with in primary care, FMGs on average earn 2.6 per cent more than USMGs. Board certification adds a premium of about $10 \%$ for primary care physicians. In the non-primary care area, however FMGs earn less than USMGs. It is likely that due to considerable overlap in FMGs and primary care physicians a lot of outcomes for foreign graduates are similar to the outcomes for primary care physicians. A board certified primary care physician earns 8 per cent more than a non-certified physician in the same field, and the difference is 13.5 per cent for nonprimary care specialists.

In column 3 of table 4 we add an interaction term for foreign graduates and primary care physicians. We can see that even though it seems that on average FMGs earn less than USMGs, the primary care FMGs perform better than their USMG counterparts which is consistent with results in column $1-2$. As mentioned earlier, the primary care specialties are low paying so they are not that sought after by the USMGs, and a FMG's priority would be to get into any residency program so they will apply to residencies with higher likelihood of acceptance. Therefore, it's likely that low ability USMGs sort into these specialties and higher ability FMGs enter primary care practice, which may explain the difference in earnings for FMGs.

Column 2 of table 4 shows that non primary care foreign trained physicians on average earn 3 per cent less than their USMGs counterparts. A possible explanation will be the older FMGs who entered USA in the 60s and 70s were considered to be less able due to fewer restrictions on entry of physicians. Entry restrictions were tightened in 1982 after concerns were raised about the quality of these physicians. We would expect to see a change in wage differential in earnings of physicians who came here before and after 1982. 
TABLE 5

\section{OLS REGRESSION OF LOG HOURLY INCOME ON PRIMARY CARE PHYSICIANS AND NON-PRIMARY CARE PHYSICIANS' DATA (BEFORE AND AFTER 1982, WHEN RESTRICTIONS WERE PLACED ON ENTRY OF FMGS)}

\begin{tabular}{|l|c|c|c|c|}
\hline & $($ Year $<1982)$ & $($ Year $>1982)$ & $($ Year $<1982)$ & $($ Year $>1982)$ \\
\hline VARIABLES & NPC & NPC & PC & PC \\
\hline FMG & & & & \\
\hline & $-0.0494 * *$ & -0.00644 & -0.0195 & $0.0365^{* * *}$ \\
\hline Experience & $(0.0231)$ & $(0.0196)$ & $(0.0298)$ & $(0.0141)$ \\
\hline & 0.00438 & $0.0614^{* * *}$ & 0.00697 & $0.0444 * * *$ \\
\hline Experience Squared & $(0.0131)$ & $(0.00507)$ & $(0.0104)$ & $(0.00418)$ \\
\hline & -0.000164 & $-0.00221^{* * *}$ & -0.000135 & $-0.00165^{* * *}$ \\
\hline Male & $(0.000260)$ & $(0.000255)$ & $(0.000206)$ & $(0.000235)$ \\
\hline & $0.221^{* * *}$ & $0.0971^{* * *}$ & $0.198^{* * *}$ & $0.0592^{* * *}$ \\
\hline Solo & $(0.0356)$ & $(0.0182)$ & $(0.0251)$ & $(0.0121)$ \\
\hline & $-0.218^{* * *}$ & $-0.150^{* * *}$ & $-0.163 * * *$ & $-0.164 * * *$ \\
\hline HMO & $(0.0193)$ & $(0.0179)$ & $(0.0212)$ & $(0.0166)$ \\
\hline & 0.00390 & 0.0268 & $0.0965 * * *$ & $0.0451^{* *}$ \\
\hline Medical School & $(0.0346)$ & $(0.0361)$ & $(0.0278)$ & $(0.0222)$ \\
\hline & $-0.368^{* * *}$ & $-0.306^{* * *}$ & -0.0235 & $-0.138^{* * *}$ \\
\hline Hospital & $(0.0374)$ & $(0.0215)$ & $(0.0417)$ & $(0.0185)$ \\
\hline & $-0.230^{* * *}$ & $-0.123^{* * *}$ & $0.0644 *$ & 0.00639 \\
\hline Other & $(0.0343)$ & $(0.0222)$ & $(0.0368)$ & $(0.0153)$ \\
\hline & $-0.229^{* * *}$ & $-0.117^{* * *}$ & -0.00807 & $-0.0498^{* * *}$ \\
\hline Board Certified & $(0.0325)$ & $(0.0244)$ & $(0.0263)$ & $(0.0175)$ \\
\hline & $0.104 * * *$ & $0.129^{* * *}$ & $0.0652^{* * *}$ & $0.136^{* * *}$ \\
\hline Constant & $(0.0340)$ & $(0.0236)$ & $(0.0224)$ & $(0.0222)$ \\
\hline & $4.090^{* * *}$ & $3.759^{* * *}$ & $3.781 * * *$ & $3.502^{* * *}$ \\
\hline Observations & $(0.165)$ & $(0.0375)$ & $(0.132)$ & $(0.0306)$ \\
\hline R-squared & 6,069 & 10,531 & 7,531 & 14,963 \\
\hline & 0.123 & 0.140 & 0.114 & 0.105 \\
\hline
\end{tabular}

Notes: The table shows the difference in earnings of primary care and non-primary care physicians before and after 1982 when entry restrictions on FMGs were tightened. We can see that younger physicians have done better in both the fields, particularly in primary care. FMG- foreign medical school graduates; PCP - primary care physician (internal medicine, family medicine, psychiatry, pediatrician, OB-Gyn)

Table 5 shows regressions of primary care and non-primary care pre and post 1982 . We can see that physicians who came to the US after 1982 do much better than physicians who came here before this time. In primary care the FMGs earn approx. 3.65 per cent more, where as in non-primary care sector the difference in earnings is slightly positive but statistically insignificant. Physicians who entered the US before 1982 in non-primary care sector earned 4.5 per cent less than USMGs. The results show that although the younger FMGs do at least as good as USMGs in non-primary care but they don't earn higher than USMGs. This indicates that something else may be going on here such as employer or customer discrimination.

It is clear that the worse labor market outcomes for FMGs is largely due to selection into low paying specialties and occupational settings. This could be self-selection by physicians and/or it could be due to institutional barriers that prevent FMGs to enter highly competitive specialty areas. 


\section{CONCLUSION}

We used CTS Physician survey data for four years to study the labor market performance of foreign medical graduates in the US. The outcome variable we use is log hourly income to run OLS regressions to compare the earnings of FMGs to USMGs. The data set is unique as it identifies physicians who went to medical school abroad and includes medical profession specific variables like practice setting, size of practice, and specialty choices of physicians, which are not available in census data. The data has never been used to study FMGs in the past. The results from the data show that FMGs seem to earn lower than USMGs but controlling for specialty choices, these differences go away. This is largely because FMGs are selecting into low paying primary care specialties that are generally less competitive than other specialties.

Selection into primary care could be a deliberate choice by FMGs or it could be a result of institutional bottlenecks to enter residency programs. If we compare these results with available statistics from the ECFMG annual report, we find that FMGs are more likely to be accepted in primary care field residency programs.

\section{REFERENCES}

Alam, A., Matelski, J. J., Goldberg, H. R., Liu, J. J., Klemensberg, J., \& Bell, C. M. (2017). The characteristics of international medical graduates who have been disciplined by professional regulatory colleges in Canada: a retrospective cohort study. Academic Medicine, 92(2), 244-249.

Baer, L. D., Ricketts, T. C., Konrad, T. R., \& Mick, S. S. (1998). Do international medical graduates reduce rural physician shortages? Medical Care, pp. 1534-1544.

Bornstein, B. H., Marcus, D., \& Cassidy, W. (2000). Choosing a doctor: an exploratory study of factors influencing patients' choice of a primary care doctor. Journal of Evaluation in Clinical Practice, 6(3), 255-262.

Center for Studying Health System Change. Community Tracking Study Physician Survey, 2004-2005: [United States]. (2008, May 14). Ann Arbor, MI: Inter-university Consortium for Political and Social Research [distributor]. https://doi.org/10.3886/ICPSR04584.v2

Center for Studying Health System Change. Community Tracking Study Physician Survey, 2000-2001: [United States]. (2008, June 18). Ann Arbor, MI: Inter-university Consortium for Political and Social Research [distributor]. https://doi.org/10.3886/ICPSR03820.v2

Center for Studying Health System Change. Community Tracking Study Physician Survey, 19981999: [United States]. (2009, February 2). Ann Arbor, MI: Inter-university Consortium for Political and Social Research [distributor], 2009-02-02. https://doi.org/10.3886/ICPSR03267.v2

Center for Studying Health System Change. Community Tracking Study Physician Survey, 1996-1997: [United States]. (2011, November 11). Ann Arbor, MI: Inter-university Consortium for Political and Social Research [distributor]. https://doi.org/10.3886/ICPSR02597.v3

Chen, P. G. C., Nunez-Smith, M., Bernheim, S. M., Berg, D., Gozu, A., \& Curry, L. A. (2010). Professional experiences of international medical graduates practicing primary care in the United States. Journal of General Internal Medicine, 25(9), 947-953.

Fordyce, M. A., Doescher, M. P., Chen, F. M., \& Gary Hart, L. (2012). Osteopathic physicians and international medical graduates in the rural primary care physician workforce. Family MedicineKansas City, 44(6), 396.

Hart, L. G., Skillman, S. M., Fordyce, M., Thompson, M., Hagopian, A., \& Konrad, T. R. (2007). International medical graduate physicians in the United States: changes since 1981. Health Affairs, 26(4), 1159-1169.

Lin, H. C., Chen, C. S., Liu, T. C., \& Lee, H. C. (2006). Differences in practice income between solo and group practice physicians. Health Policy, 79(2-3), 296-305. 
McDonald, J. T., Warman, C., \& Worswick, C. (2015). Immigrant selection systems and occupational outcomes of international medical graduates in Canada and the United States. Canadian Public Policy, 41(Supplement 1), S116-S137.

Mick, S. S., \& Lee, S. Y. D. (1997). The safety-net role of international medical graduates. Health Affairs, 16(4), 141-150.

Mullan, F., Politzer, R. M., \& Davis, C. H. (1995). Medical migration and the physician workforce: international medical graduates and American medicine. JAMA, 273(19), 1521-1527.

Norcini, J. J., Boulet, J. R., Dauphinee, W. D., Opalek, A., Krantz, I. D., \& Anderson, S. T. (2010). Evaluating the quality of care provided by graduates of international medical schools. Health Affairs, 29(8), 1461-1468.

Norcini, J. J., Boulet, J. R., Opalek, A., \& Dauphinee, W. D. (2014). The relationship between licensing examination performance and the outcomes of care by international medical school graduates. Academic Medicine, 89(8), 1157-1162.

Petterson, S. M., Liaw, W. R., Phillips, R. L., Rabin, D. L., Meyers, D. S., \& Bazemore, A. W. (2012). Projecting US primary care physician workforce needs: 2010-2025. The Annals of Family Medicine, 10(6), 503-509.

Thompson, M. J., Hagopian, A., Fordyce, M., \& Hart, L. G. (2009). Do international medical graduates (IMGs) "fill the gap" in rural primary care in the United States? A national study. The Journal of Rural Health, 25(2), 124-134.

Tsugawa, Y., Jena, A. B., Orav, E. J., \& Jha, A. K. (2017). Quality of care delivered by general internists in US hospitals who graduated from foreign versus US medical schools: observational study. bmj, 356, j273. 